\author{
Michio Banzai · Satoshi Sato · Hideo Matsuda \\ Hiroshi Kanasugi
}

\title{
Trisomy 1 in a case of a missed abortion
}

Received: 29 January 2004/ Accepted: 20 April 2004 / Published online: 8 June 2004

(C) The Japan Society of Human Genetics and Springer-Verlag 2004

\begin{abstract}
Most chromosomal trisomies lead to miscarriages. In all trisomies, trisomy 1 is the most rare case. We herein present a patient who demonstrated a gestational sac and a yolk sac on transvaginal ultrasound. However, at 53 days of gestation, the pregnancy was lost with a diagnosis of a blighted ovum. A D\&C was recommended and performed. A cytogenetic analysis from chorionic villi demonstrated a 47,XX, +1 chromosome complement in all 100 cells. Regarding full trisomy 1 , there has only been one case report of a preembryo and two case reports in a clinically recognized pregnancy to date.
\end{abstract}

Keywords Trisomy $1 \cdot$ Missed abortion

\section{Introduction}

A cytogenetic analysis of the conception products was performed, and every chromosome has now been identified in the trisomic state. Most of these chromosomal trisomies are the primary cause of pregnancy loss. In all trisomies, trisomy 1 is the most rare case. There have so far only been three case reports of a full trisomy 1 in the literature.

M. Banzai $(\bowtie) \cdot$ S. Sato $\cdot$ H. Kanasugi

Department of Obstetrics and Gynecology,

Saiseikai Yamagata Hospital, 79-1 Okimachi,

Yamagata 990-8545, Japan

E-mail: banzai@macbase.or.jp

Tel.: + 81-23-6821111

Fax: + 81-23-6820122

H. Matsuda

Department of Obstetrics and Gynecology,

National Defense Medical College,

Tokorozawa, Japan

\section{Clinical report}

Our patient (G2P0) presented for obstetric care at 33 days of gestation. Her first transvaginal ultrasound study was performed at 33 days of gestation and she showed no intrauterine gestational sac. Her serum hCG level was $160 \mathrm{mIU} / \mathrm{ml}$. A second transvaginal scan, performed at 36 days of gestation, showed a small gestational sac $(3 \mathrm{~mm})$. A third transvaginal scan, performed at 48 days of gestation, revealed the development of a sac $(7.6 \mathrm{~mm})$ and the presence of a yolk sac. A fourth transvaginal scan, performed at 53 days of gestation, showed the development of a sac $(10 \mathrm{~mm})$ without any embryonic pole development. A D\&C was thus recommended and performed. Chorionic villi were isolated from the products of conception and cultured in the two cell lines. The cell line in better condition was prepared after 12 days of culture. A cytogenetic analysis by G-banding from the chorionic villi demonstrated a 47,XX, +1 chromosome complement in all 100 cells (Fig. 1). We found no abnormalities in the features of the gestational sac and chorionic villi. In our hospital, we recommend a cytogenetic analysis of the chorionic villi for patients to obtain more information regarding their abortions. Until our first experience of a trisomy 1 , we analyzed 160 cases of miscarriages, and 74 autosomal nonmosaic trisomies were observed. From that time, 111 cases of autosomal nonmosaic trisomies have been detected; however, no case of a trisomy 1 has previously been observed.

\section{Discussion}

Most embryos with chromosome abnormalities lead to spontaneous abortions. About $70 \%$ of such abnormalities are found in spontaneously aborted fetuses. Of these, more than half of all abnormalities are autosomal trisomies. To date, trisomy was found for every autosome. However, trisomy 1 is only extremely rarely found. The first case of a full trisomy 1 was documented in an eight-cell human preembryo (Watt et al. 1987). In a 
Fig. 1 Cytogenetic analysis by G-banding from the chorionic villi demonstrated a $47, \mathrm{XX},+1$ chromosome complement in all 100 cells

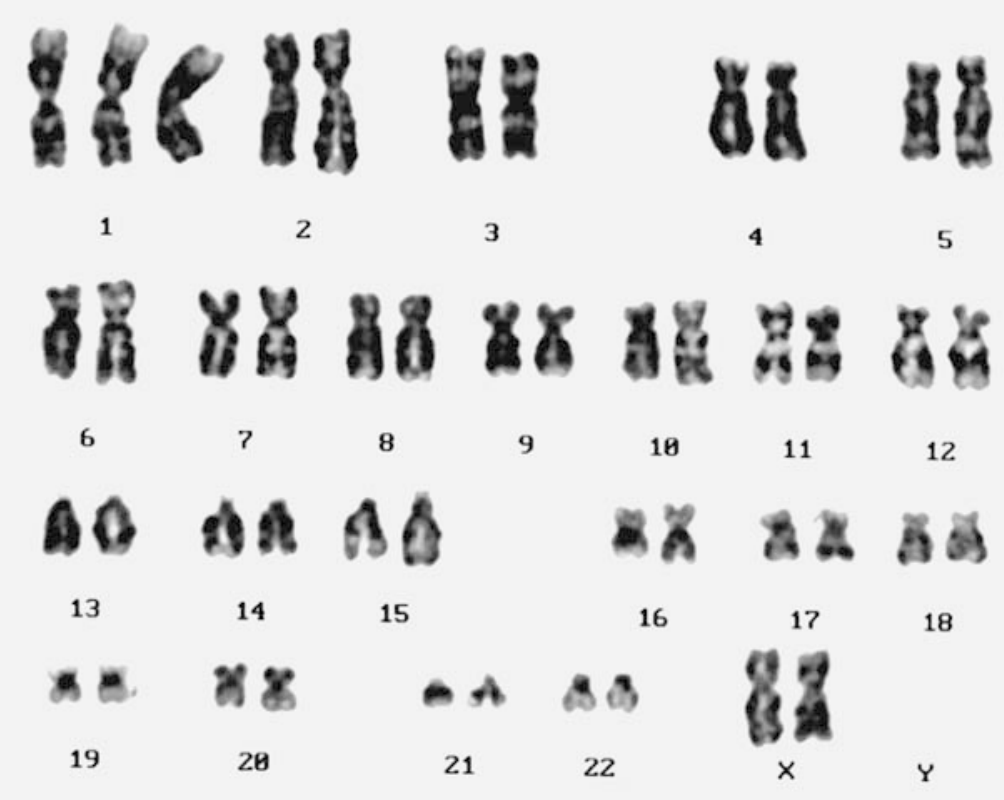

Table 1 Review of the literature of a clinically recognized pregnancy with trisomy 1. GS gestational sac, $Y S$ yolk sac, FHB fetal heart beat, $L M P$ last menstrual period

\begin{tabular}{|c|c|c|c|c|c|c|c|}
\hline \multirow{2}{*}{$\begin{array}{l}\text { No. } \\
1\end{array}$} & \multirow{2}{*}{$\begin{array}{l}\text { Series } \\
\text { Hanna et al. (1997) }\end{array}$} & \multirow{2}{*}{$\begin{array}{l}\text { Age } \\
?\end{array}$} & \multirow{2}{*}{$\begin{array}{l}\text { Pregnancy } \\
\text { Natural cycle }\end{array}$} & \multicolumn{3}{|c|}{ Development } & \multirow{2}{*}{$\begin{array}{l}\begin{array}{l}\text { Eliminated period } \\
\text { (estimated date) }\end{array} \\
\begin{array}{l}8.5 \text { weeks post-LMP } \\
\text { ( } 47 \text { days postfertilization) }\end{array}\end{array}$} \\
\hline & & & & $\mathrm{GS}(+)$ & $\mathrm{YS}(+)$ & FHB $(-)$ & \\
\hline 2 & Dunn et al. (2001) & 30 & IVF-ET & $\mathrm{GS}(+)$ & $\mathrm{YS}(+)$ & FHB (-) & 42 days postfertilization \\
\hline 3 & Present case & 30 & Natural cycle & $\mathrm{GS}(+)$ & $\mathrm{YS}(+)$ & FHB $(-)$ & $\begin{array}{l}53 \text { days post-LMP } \\
\text { (39 days postfertilization) }\end{array}$ \\
\hline
\end{tabular}

clinically recognized pregnancy with a full trisomy 1 , this is the third report (Table 1). In these three cases, the development of a gestational sac and increased hCG levels were detected. However, no embryonic pole development or fetal heart beat was observed. Theoretically, the frequencies of meiotic nondisjunction in each autosomal chromosome are equal. Therefore, trisomy 1 embryos are thought to be generally eliminated before implantation or at an early stage after implantation. However, these three embryos with trisomy 1 were not eliminated soon after implantation. We could identify no reason for the differences between the eliminated and surviving embryos with trisomy 1 . Moreover, in human beings, it is doubtful that the frequency of a meiotic nondisjunction for each autosomal chromosome is equal.
Acknowledgements We thank Chiaki Shirayori, Katsutoshi Asano, and Hiromitsu Shimada of Nihon Gene Research Labs Inc (Sendai, Japan) for cytogenetic analyses from chorionic villi.

\section{References}

Dunn TM, Grunfeld L, Kardon NB (2001) Trisomy 1 in a clinically recognized IVF pregnancy. Am J Med Genet 99:152-153

Hanna JS, Shires P, Matile G (1997) Trisomy 1 in a clinically recognized pregnancy. Am J Med Genet 68:98

Watt JL, Templeton AA, Messinis I, Bell L, Cunningham P, Duncan RO (1987) Trisomy 1 in an eight cell human pre-embryo. J Med Genet 24:60-64 